\title{
Diffusion Rate and Activity Index of Some Slow Release Nitrogen Fertilizers
}

\author{
S. T. Abou-Zied", Hanem A. Sibak ${ }^{* *}$, Amal L. Abd El-Latif" and R. E. Essa ${ }^{* * * *}$ \\ *Soil Sci. Dept., Fac. of Agric., Cairo Univ., Giza, Egypt \\ ${ }^{* *}$ Chemical Eng. Dept., Fac. of Eng., Cairo Univ. Giza, Egypt \\ *** Field Crops Res. Dept., National Research Centre, Giza, Egypt
}

$\mathbf{T}$

RIALS were conducted to produce certain local slow release fertilizers using either synthetic or natural materials. The prepared fertilizers were evaluated in the laboratory by calculating their activity index and diffusivity. The results showed that coating urea fertilizers with sulphur, phosphogypsum or bentonite leads to clear depression in the amounts of released nitrogen. The highest effect found was with both imported sulphur coated urea (SCU) followed by bentonite coated urea (BCU), then phosphogypsum coated urea (PGCU). The results indicate that the diffusivity is nearly constant for thickness of sulphur $404.67 \mathrm{~cm}^{2} / \mathrm{sec}$ and then it begins to decrease after one day dissolution time. This may be attributed to the fact that after certain dissolution time a shrinkage occur resistant to dissolution may be formed which inhibit the dissolution characteristics. Observed that an average value of 483.09 $\mathrm{cm}^{2} / \mathrm{sec}$ may be considered as diffusivity of urea through solid bentonite. From which it may be observed that an average value of $704.80 \mathrm{~cm}^{2} / \mathrm{sec}$ may be considered as diffusivity of urea through solid phosphogypsum. This can be attributed to the fact that the coating layer of urea formed by speaking resistant to degradation by the characteristics of each material.

Keywords: Activity index, Diffusivity. Sulphur coated urea (SCU), Phosphogypsum coated urea $(\mathrm{PGCU})$ and Bentonite coated urea $(\mathrm{BCU})$.

\section{Introduction}

The fertilizer industry faces a continuing challenge to improve its products to increase the efficiency of their use, particularly of nitrogenous fertilizers, and to minimize any possible adverse environmental impact. This is done either through improvement of fertilizers already in use, or through development of new specific fertilizer types.

Slow release fertilizers have become essential for agriculture development especially under conditions of high nutrient losses. Advantages of slow release fertilizers are; a) relatively high efficiency of nutrient uptake by plants, b) minimization of losses through leaching and volatilization especially under flooded and alkaline conditions, c) more uniform growth of plants through the season without repeated application of fertilizers, d) elimination of luxury consumption of fertilizers by plants, f) prevention of burning of vegetation or damage to germination of seeds.
In recent years, there has been a considerable research dealing with the development of methods for production of slow release fertilizers by taking advantages of physical and/or chemical properties of certain compounds. Vashishtha et al. (2010) showed that wet method is better than dry method and $1.7 \mathrm{~mm}$ diameter size particle give better results than $1.4 \mathrm{~mm}$ size diameter particle. Dissolution rate, which is directly related to the nitrogen use efficiency, is reduced as a result of coating, thus giving coated urea high moisture holding capacity. The mechanism of slow release fertilizers enables an increase in the effectiveness of the utilization of nutrients from fertilizer when growing potted plants. Slow release fertilizer is based on the granules coated with many different materials as acrylamid copolymer, wax resin, natural rubber, polyvinyl chloride, and polylactic acid (Arrobas et al., 2011). Puchades et al. (1984) compared sulphur coated urea (SCU) with ammonium sulphate granules (AS) in regard to nitrogen release and diffusion. Nitrogen release from the SCU was slow and 
after three months $29.5 \%$ of applied $\mathrm{N}$ remained in the granules. At the end of the experiment there was a deficit to $37.1 \% \mathrm{~N}$ in the case of the AS granules while there was virtually none with the SCU. Sibak (1985) studied the diffusion characteristics of urea through sulphur and gypsum in an experiment that carried out using different practical and theoretical methods from which the diffusivity of urea through sulphurs was found to be equal to $47.5(10)^{-10} \mathrm{~cm}^{2} / \mathrm{sec}$, and the diffusivity of urea through gypsum was found using the same theoretical and practical technique to be equal to $1080(10)^{-10} \mathrm{~cm}^{2} / \mathrm{sec}$ by applying Fick's law. El-Leboudi, et al. (1997) found that the activity index (AI) values varied between 34 and $74 \%$ for the studied fertilizers, the lowest values being found with (UF) fertilizers while imported plantacote (PC) giving the highest values. Ni et al., (2013) showed that the release of S-urea was not based on Fickian diffusion but underwent anomalous diffusion with its release rate was mainly affected by the dissolving eroding process of the medium which was controlled by the compactness of the lattice structure. This process may be strengthened by increasing the amount of bentonite. Thanh et al. (2013) indicated that releasing time increases as effective diffusivity coefficient decreases. Releasing time was 8.34 days with a diffusivity coefficient of $1.60 \times 10^{-13} \mathrm{~m}^{2} / \mathrm{s}$ and 132.96 days with diffusivity coefficient of $10^{-14} \mathrm{~m}^{2} / \mathrm{s}$. It demonstrated that material chosen for urea coating would have a diffusion coefficient of 1.49 $\mathrm{x} 10^{-14} \mathrm{~m}^{2} / \mathrm{s}$ to obtain a suitable releasing time for effective fertilization. Wang et al. (2013) showed that the nitrogen accumulative dissolution rate of all tested fertilizers in static water at $25^{\circ} \mathrm{C}$ were less than $75 \%$ after $28^{\text {th }}$ day. Nitrogen dissolution curves of SCU in static water showed a similar tendency to those grown in soil (substrate), whereas the nitrogen dissolution curves of ureaform UF) and isobutylendene diurea (IBDU) had significant difference between the two conditions. The nitrogen cumulative dissolution rates of all tested fertilizers in substrates were less than in soil, and in pot culture of lawn grass showed higher tendency than in that of melon. The objective of this study is to produce some slow release fertilizers using both synthetic and natural materials. Moreover, investigate the diffusion and activity index (AI) of them.

\section{Materials and Methods}

The experimental work has been designed to synthesize and evaluate some slow release fertilizers. Three kinds of trials were conducted to include preparation of some various forms of slow release fertilizers. Laboratory evaluation for the release of nitrogen from indicated prepared fertilizers along with those of sulphur coated urea $(\mathrm{SCU})$, bentonite coated urea $(\mathrm{BCU})$ and phosphogypsum coated urea (PGCU) as well as urea.

\section{Materials used}

The most important way of controlling fertilizer dissolution in water is by coating fertilizer crystals with different coatings:

\section{Urea (U) $\mathrm{NH}_{2} \mathrm{CONH}_{2}$}

This is a product of EL-Nasr Company for Chemical Fertilizers consist of white granules having the following specifications:
○ M. wt.
60.06
- Assay min.
$99 \%$
- Melting point
$130-134^{\circ} \mathrm{C}$

Sulphur (S)

The sulphur used is a yellow powder having the following specifications:
○ M. wt.
32
- Melting point $150^{\circ} \mathrm{C}$
- Sulphur $\quad 80 \%$

Bentonite (B)

Bentonite shale was obtained from Quasr El-Sagha (El-Fayoum Governorate); Table (1) shows some physical and chemical analyses for bentonite.

\section{Phosphogypsum ( $P G)$}

Phosphogypsum shale obtained from AbuZaabal Company for fertilizers; Table (1) shows some physical and chemical analyses of phosphogypsum.

Manufacturing process of slow release fertilizers

Several attempts were made to produce SCU, BCU and PGCU through coating with materials imposing their function physically. Several laboratory trials were carried out to synthesize sulphur, phosphogypsum and bentonite containing $20 \%$ pure coating material in a fine form. This was based on the idea of the physical incorporation of some completely soluble compounds containing $\mathrm{N}$, such as urea, in a media of coating material.

Urea was heated for $20 \mathrm{~min}$. and then receiving a mixture of conditioner and coating material, the whole being stirred for 30-40 min. to be finally removed to a drum. By heating to $70-80^{\circ} \mathrm{C}$ and 
stirring again, the mixture in another drum was mixed with wax for 20-30 min. The final product was air dried for one day, and sieved as shown in Fig. 1 according to the method given by Oertli (1980) and Trenkel (2010).

\section{Evaluation of the concerned slow release} fertilizers

Activity (AI) and availability (AVI) indices

To determine the cold water insoluble nitrogen (CWIN), $1.0 \mathrm{~g}$ samples from the concerned fertilizers were placed in $50 \mathrm{ml}$ beakers then received $20 \mathrm{ml}$ volumes of distilled water at $25 \pm 2^{\circ} \mathrm{C}$ and the mixture allowed standing for 15 minutes with occasional stirring, and finally the supernatant being decanted onto suitable filter paper. The process of decantation was repeated five times. The residue was quantitatively transferred to the filter paper to be washed several times as to receive a total volume of $250 \mathrm{ml}$ subjected to the required $\mathrm{N}$ analysis representing the so-called cold water soluble nitrogen (CWSN). Finally, total $\mathrm{N}$ percent in the washed residue was evaluated to represent the so-called cold water insoluble nitrogen (CWIN).

TABLE 1. Some physical and chemical properties of bentonite and phosphogypsum

\begin{tabular}{|c|c|c|c|}
\hline \multicolumn{2}{|c|}{ Bentonite } & \multicolumn{2}{|c|}{ Phosphogypsum } \\
\hline Characteristics & Value & Characteristics & Value \\
\hline Sand $(\%)$ & 10.24 & pH $(1: 2.5)$ & 4.00 \\
\hline Silt (\%) & 20.20 & EC (1:5) (dS/m) & 0.37 \\
\hline Texture & Clay & $\mathrm{CaSO}_{4} \cdot 2 \mathrm{H}_{2} \mathrm{O}$ & 73.32 \\
\hline O. M. (\%) & 0.24 & $\mathrm{Ca}^{2+}(\%)$ & 22.34 \\
\hline $\mathrm{CaCO}_{3}(\%)$ & 7.52 & $\mathrm{SO}_{4}^{2-}(\%)$ & 69.32 \\
\hline $\mathrm{Ca}^{2+}(\mathrm{meq} / \mathrm{l})$ & 12.00 & $P(\%)$ & 0.81 \\
\hline $\mathrm{Mg}^{2+}(\mathrm{meq} / \mathrm{l})$ & 3.70 & K (\%) & 0.03 \\
\hline $\mathrm{Na}^{+}(\mathrm{meq} / \mathrm{l})$ & 11.00 & $\mathrm{Fe}(\%)$ & 0.05 \\
\hline $\mathrm{K}^{+}(\mathrm{meq} / \mathrm{l})$ & 0.60 & & \\
\hline $\mathrm{SO}_{4}^{2-}(\mathrm{meq} / \mathrm{l})$ & 22.40 & & \\
\hline N (mg/kg) & 327.00 & & \\
\hline P (mg/kg) & 3.12 & & \\
\hline K(mg/kg) & 170.00 & & \\
\hline
\end{tabular}

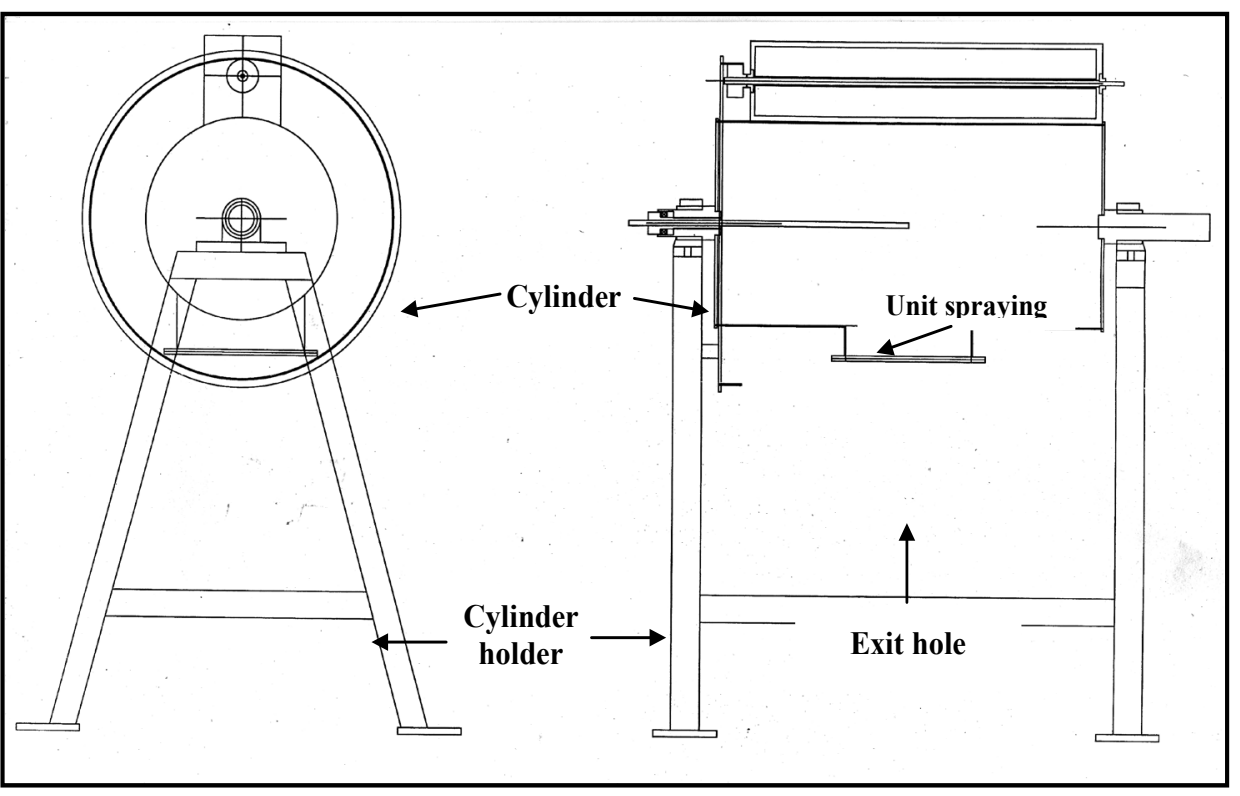

Fig. 1 Apparatus for slow release coated fertilizers manufacturing 
For determination of hot water insoluble nitrogen (HWIN), $0.3 \mathrm{~g}$ sample of residue was placed in a $400 \mathrm{ml}$ glass beakers and received $250 \mathrm{ml}$ volumes of boiling phosphate buffer solution $\left(1.43 \mathrm{~g} \mathrm{KH}_{2} \mathrm{PO}_{4}+9.10 \mathrm{~g} \mathrm{~K}_{2} \mathrm{HPO}_{4}\right.$ in one litre of water) with $\mathrm{pH}$ adjusted to 7.5 by hydrochloric acid $0.54 \mathrm{~N}$. Stirring was performed for the beakers which were then immersed, after being covered, in a boiling water bath so that the liquid in the beakers is below the water line in the bath. The mixture was stirred for about $5 \mathrm{sec}$. at time intervals of 10, 20,30 min., respectively and finally the beakers were removed and filtration being directly performed. The insoluble residue was washed four times to be finally subjected for total $\mathrm{N}$ analysis to obtain the so-called hot water insoluble nitrogen (HWIN).

Activity and availability indices were introduced by Kralovec and Morgan (1954) for the evaluation of slow release nitrogen fertilizers. these parameters were calculated using the following equations:

Where

$$
\begin{aligned}
& \mathrm{AI}=(\mathrm{CWIN}-\mathrm{HWIN}) / \mathrm{CWIN} * 100 \\
& \mathrm{AVI}=(\mathrm{CWIN}-\mathrm{HWIN}) /(\text { Total }-\mathrm{N}) * 100
\end{aligned}
$$

Where:

- $\quad$ CWIN = cold water insoluble nitrogen.

- HWIN $=$ hot water insoluble nitrogen.

○ AVI =Availability index.

$\circ$ AI =Activity index.

\section{Diffusivity}

The diffusivity of urea through solid sulphur conditioner coatings was determined according to Fick's law method

The resistance of urea diffusion is considered to be two resisting medium : the first is the resistance through the solution $\left(\mathrm{R}_{1}\right)$ and the second is the resistance through the coating layer $\left(R_{2}\right)$.Then the total resistance to urea flow will be $(\mathrm{R})$. The rate of urea diffusion was determined using the following equation.

$$
\mathbf{N}_{\mathrm{A}}=1 / \mathbf{R} *\left(\mathrm{C}_{\mathrm{s}}-\mathbf{C}_{1}{ }^{-}\right) \mathbf{A}^{-}
$$

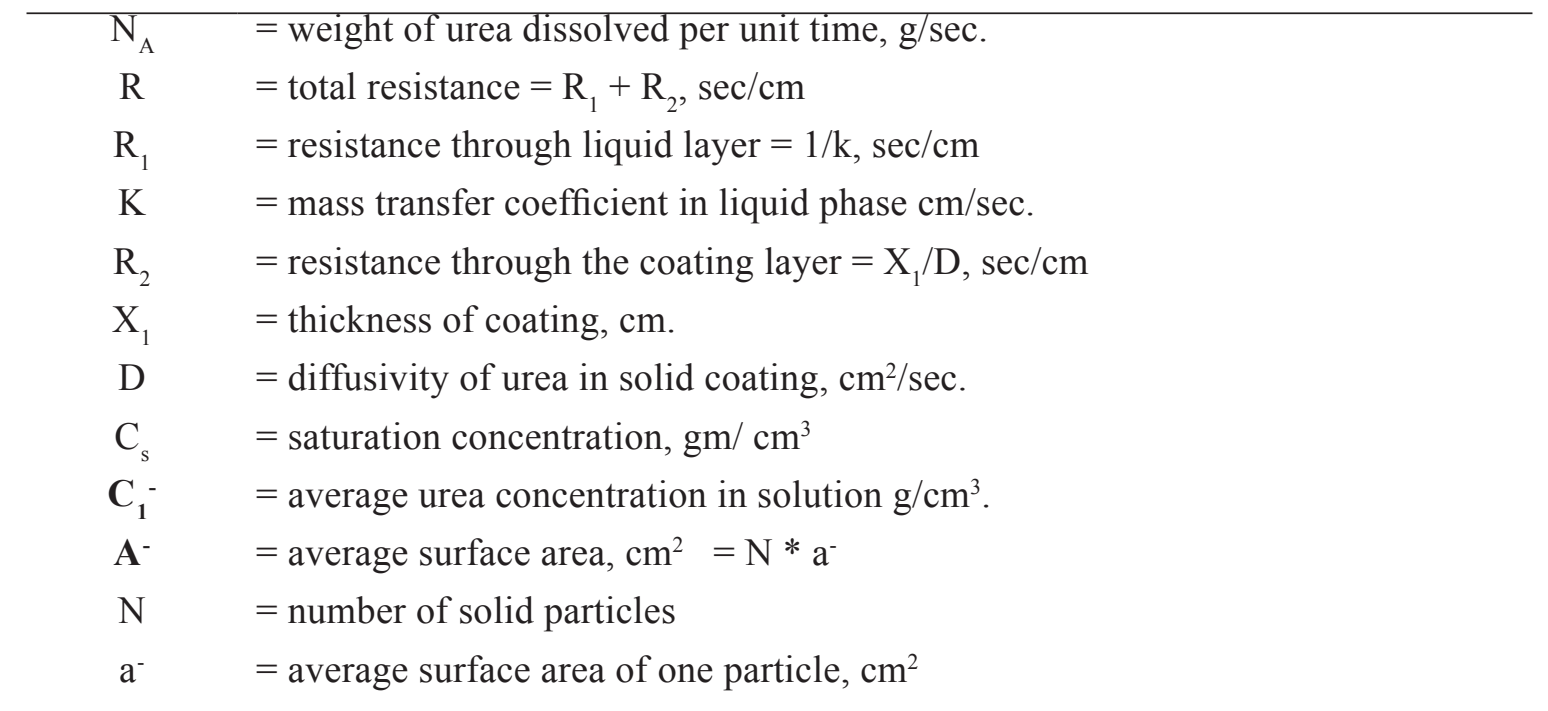

The problem to be solved first is the determination of $\mathrm{K}$, the mass transfer coefficient of urea through the liquid layer, this may be determined from the rate of dissolution determined practically as shown in Fig. 2.

$$
\left.\mathbf{N}_{\mathrm{A}}=\mathbf{k} \mathbf{A}^{=}\left\{\mathrm{C}_{\mathrm{s}}-\left(\mathrm{C}_{\mathrm{o}}+\mathrm{C}_{\mathrm{\theta}}\right) / 2\right)\right\}
$$

Where

$\begin{array}{cl}\mathrm{A}^{=} & =\text {surface area of uncoated urea } \\ \mathbf{C}_{\mathbf{\theta}} & =\text { average slope of dissolution curve of urea } \\ \mathbf{C}_{\mathbf{0}}=0 & \end{array}$

\section{Results and Discussions}

Activity index (AI)

The hot water insoluble nitrogen (HWIN) was considered as the difficult available nitrogen, while the difference between cold water insoluble nitrogen and hot water insoluble 
nitrogen was considered as slowly available nitrogen. Subtracting the cold water insoluble nitrogen (CWIN) from the total nitrogen gives the readily available nitrogen. Data in Fig.(2) indicate that the so-called (CWIN) ranged from 6.00 to 43.13 and the corresponding value for the difficult available nitrogen (HWIN) ranged from 2.00 to $19.10 \mathrm{~g}$.

The obtained data show that BCU fertilizer contained the lowest value of the difficultly available nitrogen whereas SCU having the highest value of this fraction.

The obtained data are reflected by the AI value which varied between $55.72 \%$ and $71.56 \%$. SCU fertilizer has the lowest percent of AI while PGCU has the highest one. In this respect, the tested fertilizers could be arranged as follows:

$$
\text { PGCU > BCU > SCU }
$$

These values go along with those of Gati (1979) who found that the optimal AI range had the lowest values indicating slow dissolution rates. Almost similar results were obtained by El-Leboudi et al. (1997) concerning AI whose values ranged between $34.0 \%$ and $74.0 \%$.

Regarding the availability index (AVI) which representing the slowly available nitrogen, the highest value was encounted with SCU while the lowest ones was obtained with BCU. In general the tested fertilizers could be arranged according to their availability index (AVI) as follows: SCU $>$ PGCU > BCU . The obtained data agree with Awad (1990).

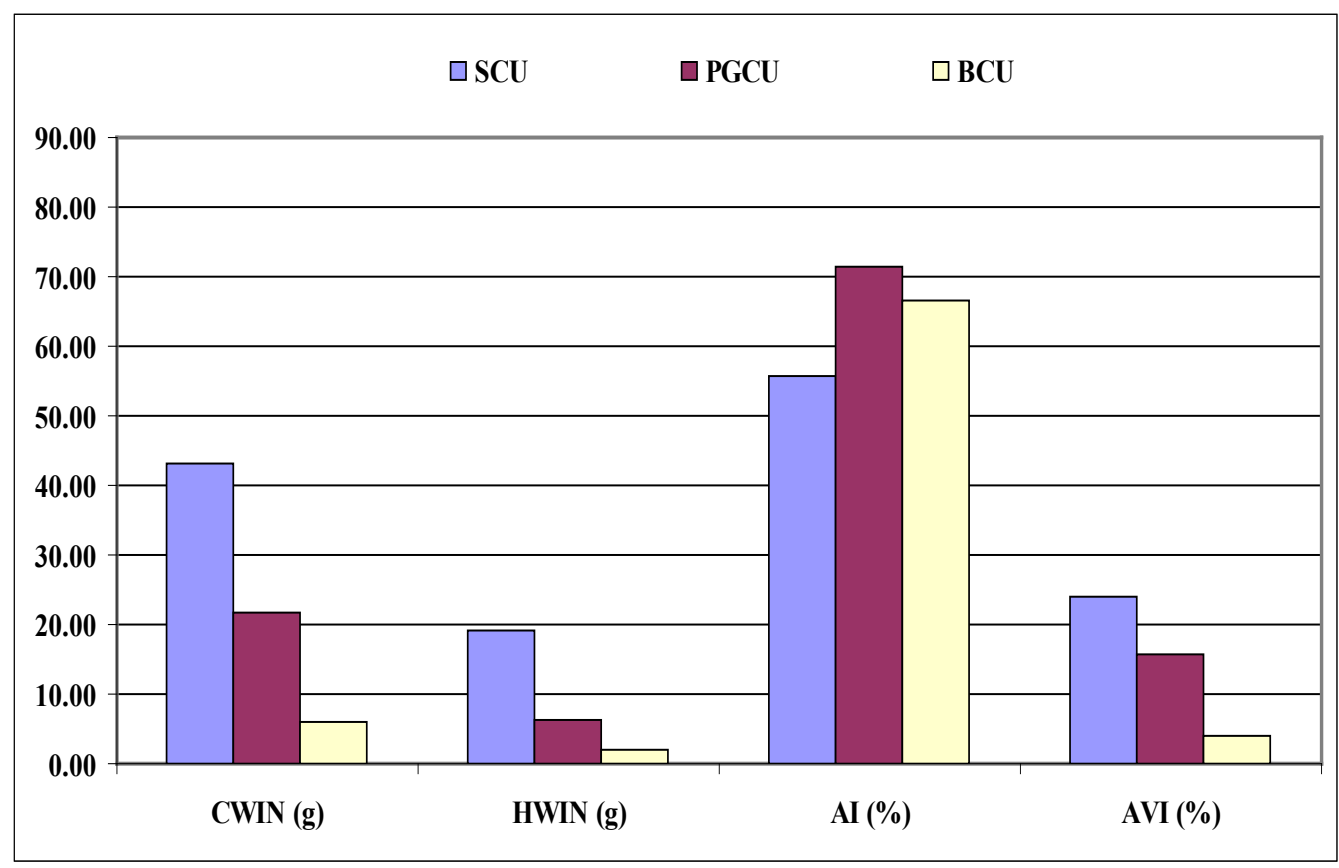

Fig. 2. Activity (AI) and availability indices (AVI) of slow release $\mathbf{N}$ fertilizers

\section{Diffusivity}

Effect of time on the dissolution of urea coated with sulphur, phosphogypsum and bentonite.

The effect of time on the dissolution of urea coated with sulphur, phosphogypsum and bentonite was studied using 10 gram of urea samples with particle size $(0.40 \mathrm{~cm})$ and coat thickness $(0.10 \mathrm{~cm})$ of the used materials at $25^{\circ} \mathrm{C}$. The dissolution percentage of urea was determined at different times using the specific gravity data as shown below in Fig. 3 from which the mass of urea dissolved is consequently determined as well as weight percent of the dissolved urea.
Result in Fig. 3 showed that the solubility and the dissolution of urea from all studied fertilizer types increased with time, however, the rate of increase of urea solubility and dissolution was higher with coated types than uncoated comparing the total amount of urea which solubilized in water. It is evident from the obtained data that total amount of urea solubilized in water was higher in the case of uncoated urea compared with the coated urea forms.

Data in Fig. 3 showed that the sulphur coat decrease the dissolution and the solubility of urea in water and is dependent on time. The obtained data agree with those obtained by Puchades et 
al. (1984) and Wang et al. (2013) who showed that the nitrogen release from the SCU was slow and after three months about $29.5 \%$ of applied $\mathrm{N}$ remained in the granules and that the dissolution rate of all tested fertilizers in static water at $25^{\circ} \mathrm{C}$ were less than $75 \%$ after the $28^{\text {th }}$ day.

The dissolution of urea from phosphogypsum coat is higher than that with sulphur coat of the same thickness $(0.10 \mathrm{~cm})$, same particle size of urea $(0.40 \mathrm{~cm})$ and at the same temperature $25^{\circ} \mathrm{C}$, this may be due to the high porosity of the used phosphogypsum coat. These values go along with those of Jarrell and Boersma (1980) and Xia et al. (2011) who showed that phosphogypsum with nitrogen fertilizers had an excellent slow release and long term performance. Phosphogypsum coating decrease the solubility of urea in water. The application of bentonite, hemihydrates phosphogypsum and starch adhesive increase the strength and gelling property of fertilizers.

The dissolution of urea through bentonite coat was higher than that of sulphur coat, whereas it was lower than that of phosphogypsum coat. The effectiveness of the used coating materials on the dissolution of urea could be arranged at descending order as follows:

Sulphur coat $>$ Bentonite coat $>$ Phosphogypsum coat

The obtained data agree with those obtained by Xia et al. (2011) who found that coating urea fertilizer with bentonite had an excellent slow release and long term performance. The application of bentonite, hemihydrates phosphogypsum and starch adhesive increase the strength and gelling property of fertilizers.Results are tabulated in Table 2.

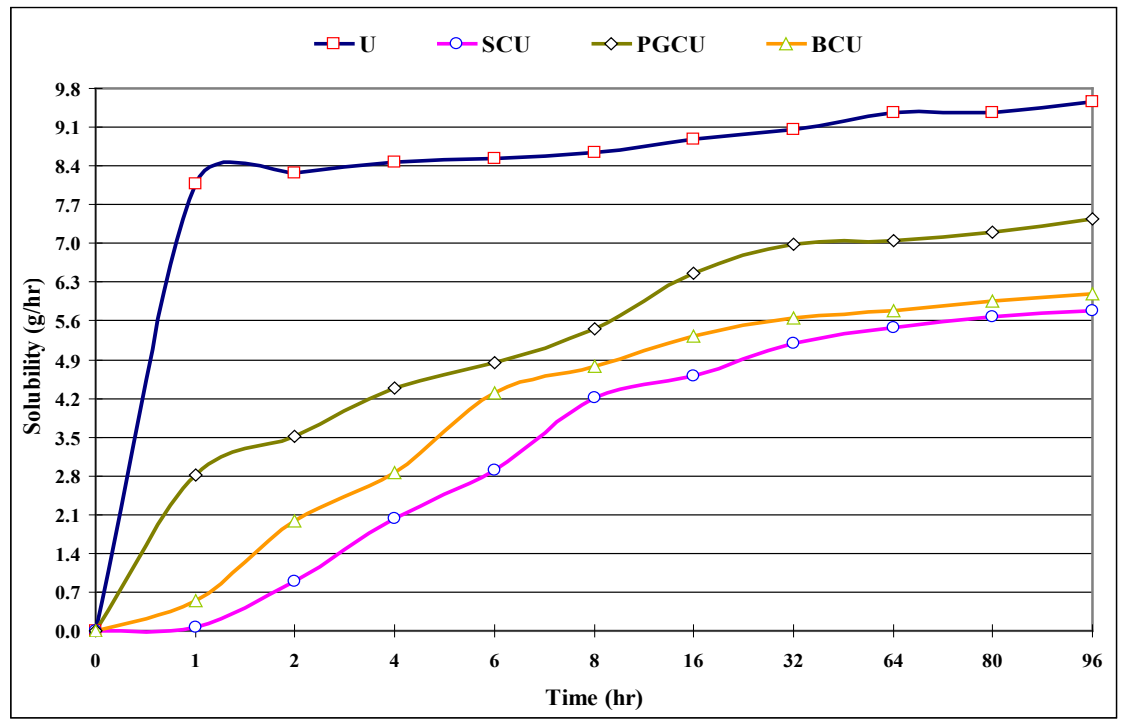

Fig. 3. Effect of time on the dissolution of urea coated with sulphur, phosphogypsum and bentonite in water

TABLE 2. Determination of the mass transfer coefficient of urea through water

\begin{tabular}{|c|c|c|}
\hline Time (hr) & $\mathrm{K}(\mathrm{cm} / \mathrm{hr})$ & $\mathrm{K}(10)^{-5}(\mathrm{~cm} / \mathrm{sec})$ \\
\hline 1 & 0.32 & 8.97 \\
\hline 2 & 0.33 & 9.19 \\
\hline 4 & 0.34 & 9.40 \\
\hline 6 & 0.34 & 9.49 \\
\hline 8 & 0.35 & 9.60 \\
\hline 16 & 0.36 & 9.87 \\
\hline 32 & 0.36 & 10.10 \\
\hline 64 & 0.37 & 10.40 \\
\hline 80 & 0.37 & 10.40 \\
\hline 96 & 0.38 & 10.60 \\
\hline Mean & 0.35 & 9.80 \\
\hline
\end{tabular}

Egypt. J. Soil Sci. 58, No. 2 (2018) 
Figure 4 showed that the diffusivity from sulphur coat ranged from 770.00 after one hour to $3.22 \mathrm{~cm}^{2} / \mathrm{sec}$ after 96 hour with an average of $404.67 \mathrm{~cm}^{2} / \mathrm{sec}$. This may be attributed to the fact that after certain dissolution time (one day), a shrinkage occur resistant to dissolution may be formed which inhibit the dissolution characteristics. Ni et al. (2013) showed that the release of sulphur coated urea diffusion with its release rate was mainly affected by the dissolving eroding process of the medium which was controlled by the compactness of the lattice structure. These values go along with those of Sibak (1985) who found the diffusivity of urea through sulphurs equal to $47.5(10)^{-10} \mathrm{~cm}^{2} / \mathrm{sec}$. Thanh et al., (2013) indicated that the releasing time increases as effective diffusivity coefficient decreases. Releasing time was 8.34 days with a diffusivity coefficient of $1.60 \times 10^{-13} \mathrm{~m}^{2} / \mathrm{sec}$ and 133.0 days with diffusivity coefficient of $10^{-14}$ $\mathrm{m}^{2} / \mathrm{sec}$.

In addition, the diffusivity of urea from bentonite coat is nearly constant, where it ranged from $838.00 \mathrm{~cm}^{2} / \mathrm{sec}$ after one hour to $27.90 \mathrm{~cm}^{2} / \mathrm{sec}$ after 96 hour with an average of $483.09 \mathrm{~cm}^{2} / \mathrm{sec}$. This process may be strengthened by increasing the amount of the dissolution may be formed which inhibit the dissolution characteristics bentonite. Glaser et al. (1987) found that the release of $\mathrm{N}$ from a polymer coated urea is time dependent. The time dependence introduced the experimentally observed lag period in the simulated release curve, which could not be predicted by simply applying Fick's law.

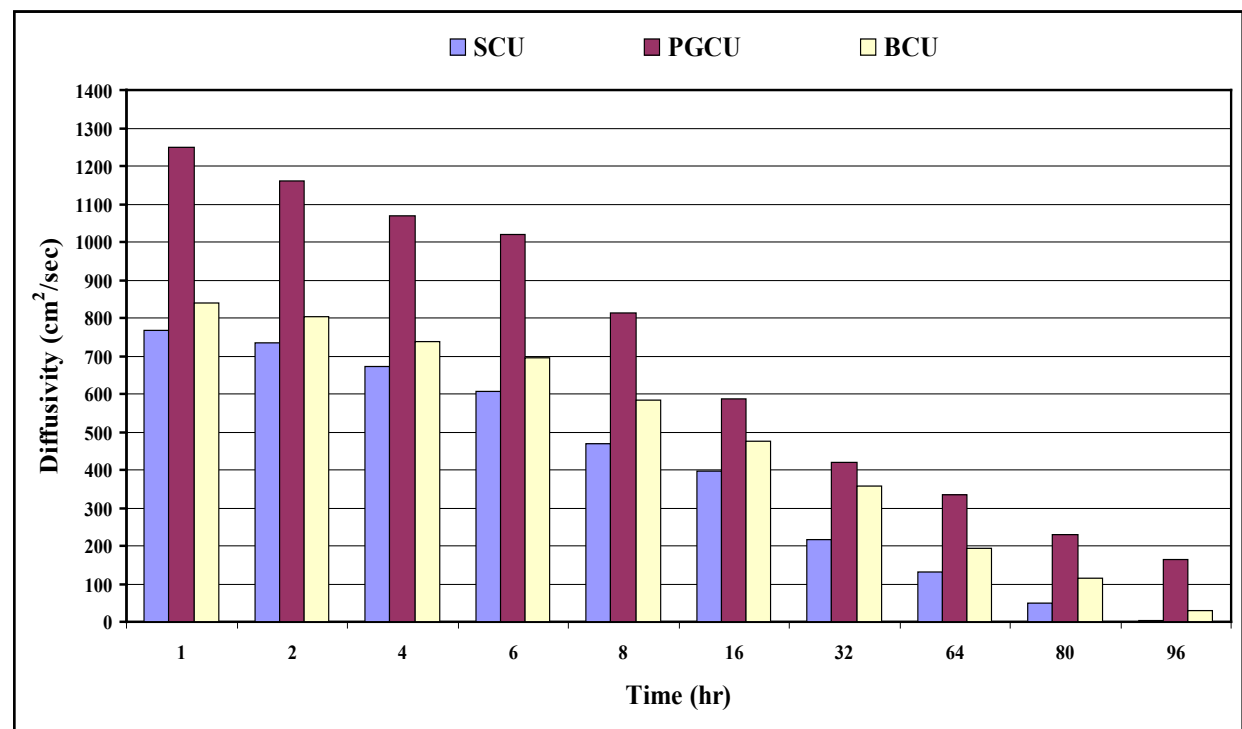

Fig. 4. Effect of time on the diffusivity $\left(\mathrm{D}=\mathrm{cm}^{2} / \mathrm{sec}\right)$ of urea through sulphur, phosphogypsum and bentonite coat

Regarding the diffusivity of urea from phosphogypsum coat,it is nearly constant where it ranged from $1250.00 \mathrm{~cm}^{2} / \mathrm{sec}$ after one hour to $164.00 \mathrm{~cm}^{2} / \mathrm{sec}$ after 96 hour with an average of $704.80 \mathrm{~cm}^{2} / \mathrm{sec}$. These values go along with those of Sibak (1985) who found the diffusivity of urea through gypsum was found using the same practical technique to be equal to $1080(10)^{-10} \mathrm{~cm}^{2} / \mathrm{sec}$ by applying Fick's law.

\section{References}

Arrobas, M.; Parada, M.J.; Magalhaes, P. and Rodrigues, M.A. (2011) Nitrogen use efficiency and economic efficiency of slow release $\mathrm{N}$ fertilisers applied to irrigated turfs in a Mediterranean environment.
Nutr. Cycling in Agroeco systems, 89,329-339.

Awad, E.(1990) Effect of veterra hydrogel and nitrogen fertilizers on wheat. Zagazig J.Agric. Res. 17 (4B):1425-1431.

EL- Leboudi, A.E.; Awad, F.; EL- Sebaay, A.S. and EL- Ashry, S.M. (1997) Preparation and laboratory evaluation of some slow release fertilizers under Egyptian conditions. Egypt. J. Soil Sci., 37, 329341.

Gati, F. (1979) Urea aldehyde condensation products as fertilizers and their effect on calcareous sandy soils. Acta Agronomica. Academiae Scietiarum Hungaricae, 28,150-157.

Egypt. J. Soil Sci. 58, No. 2 (2018) 
Glaser, V.; Stajer, P. and Vidensky, J. (1987) Simulace prubehu rozpousteni obalovanych prumyslovych hnojiv ve vode $\square$ II. Chemicky Prumysl. 37 (62), 353-355.

Jarrel, W.M and Boersma, L. (1980) Release of urea by granules of sulphur coated urea. Soil Sci. Soc. Amer. J. 44, 418-422.

Kralovec, R. D. and Morgan, W. A. (1954) Condensation products of urea and formaldehyde as fertilizer with controlled nitrogen availability. $J$. Agric. Food Chem. 2, 92-95.

Ni, X.; Wu, Y.; Wu, Z.; Wu, L.; Qiu, G. and Yu, L. (2013) Anoval slow release urea fertilizers: physical and chemical analysis of its structure and study of its release mechanism. Biosystem Eng. 115, 274-282.

Oertli, J.J. (1980) Controlled release fertilizers. Fert. Res. 1,103-123.

Puchades, R.; Yufera, E. P.; Maquieira, A. and Rubio, L. (1984) Soil nitrogen fluctuations in citrus plots fertilized with sulphur coated urea and ammonium nitro sulphate. J. Plant Soil, 78, 357-65.

Sibak, A. H. (1985) Studies on slow release fertilizers. M.Sc. Thesis, Fac. of Engineering, Cairo Univ., Egypt.
Thanh H. T.; Ku, Z. K. S.; Anis, S. B. S. and Lukman, B. I. (2013) Modeling of Urea Release from Coated Urea for Prediction of Coating Material Diffusivity. Proceedings of the $6^{\text {th }}$ International Conference on process systems engineering (PSE ASIA) 25 - 27, Kuala Lumpur.

Trenkel, M.E. (2010) Slow and Controlled Release and Stabilized Fertilized: An Option for Enhancing Nutrient Use Efficiency in Agriculture. Intern. Fert. Industry Assoc. (IFA), Paris, France, pp.163.

Vashishtha, M.; Dongara, P. and Singh, D. (2010) Improvement in properties of urea by phosphogypsum coating. International J. of Chem. Tech Res., 2(1)36-49.

Wang, X.; Kuai, J.; Liu, X.;Ye, F. and Zhang, J. (2013) Nutrient release characteristics of four slow and controlled release nitrogen fertilizer in different environmental conditions. Acta Agrestia Sinica -02

Xia,A. ; Deng, Y. ;Dong, F. and Yang, R.X.C.(2011) Study on phosphogypsum-based slow release nitrogen fertilizer. J. of Non- Metallic Mines,(4), 437-439.

(Received:30/3/2016; accepted:15/5/2016) 


\section{معدل الانتشار ودليل النشاط لبعض الأسمدة النيتزوجينية بطيئة الإمــاد}

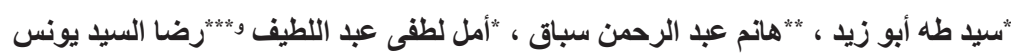

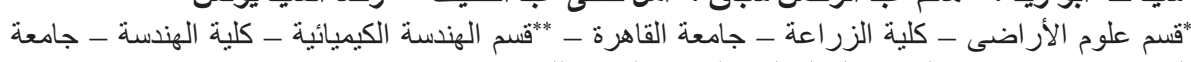

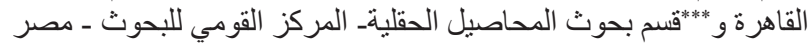

أجريت بعض التجارب لإنتاج الأسمدة بطيئة الإمداد بإبتخدام بعض المو اد المحلية الصناعية أو الطبيعية. وتم

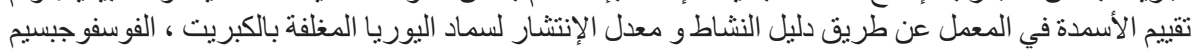

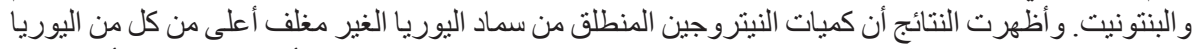

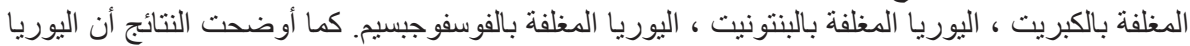

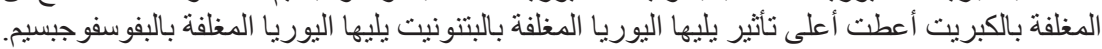

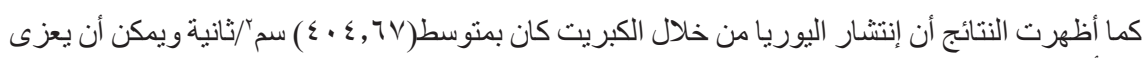

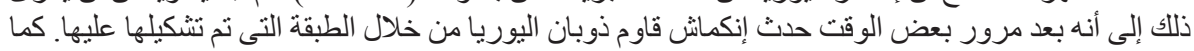

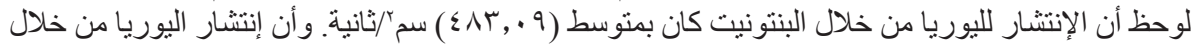

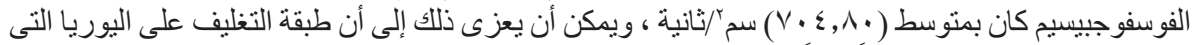
تم تثكيلها قاومت الذوبان نسبياً طبقاً لخصائص المادة المغلفة. 